\title{
Synthetic E-selectin prevents postoperative vascular restenosis by inhibiting nuclear factor $\kappa B$ in rats
}

\author{
JIANGANG LIU $^{1 *}$, ZHONGJIE LIU $^{2 *}$, XIAOHUI HU ${ }^{1 *}$, YUAN ZHANG ${ }^{3}$ and SHIMING ZHANG ${ }^{1}$ \\ ${ }^{1}$ Department of Neurosurgery, The First Affiliated Hospital of Soochow University, Suzhou, \\ Jiangsu 215006; ${ }^{2}$ Department of Neurosurgery, Shiqianxian People's Hospital, Guizhou 555100; \\ ${ }^{3}$ Department of Radiology, Suzhou Guangji Hospital, Suzhou, Jiangsu 215006, P.R. China
}

Received April 5, 2016; Accepted March 21, 2017

DOI: $10.3892 / \mathrm{mmr} .2018 .8536$

\begin{abstract}
During the development of postoperative vascular restenosis, the aberrant proliferation of vascular smooth muscle cells (VSMCs) is a critical event resulting in intimal hyperplasia. Inflammatory responses involving the activation of nuclear factor (NF)- $\kappa \mathrm{B}$ are among the major molecular processes underlying restenosis. The present study aimed to investigate the roles of $\mathrm{NF}-\kappa \mathrm{B}$ in VSMC proliferation and restenosis following vascular anastomosis, as well as to evaluate the potential of synthetic E-selectin to downregulate NF- $\mathrm{NB}$ and thus inhibit vascular hyperplasia. A total of 72 adult male Sprague-Dawley rats were randomly assigned to three groups: Control, operation and treatment groups. Rats in the operation and treatment groups received longitudinal incisions in the right carotid arteries, which were closed using interrupted sutures. Following vascular anastomosis, synthetic E-selectin $(10 \mathrm{mg} / \mathrm{kg})$, or an equal volume of saline, was immediately injected into the right femoral vein of rats in the treatment and operation groups, respectively. Following surgery, the mRNA and protein expression levels of NF- $\kappa \mathrm{B}$ at the site of anastomosis, the levels of tumor necrosis factor- $\alpha$ and interleukin- 6 in the serum, NF- $\kappa \mathrm{B}$ binding activity, and the presence of proliferating cell nuclear antigen (PCNA)-positive cells were evaluated by western blotting, reverse transcription-quantitative polymerase chain reaction, ELISA, electrophoretic mobility shift assay and immunofluorescence staining. The present results demonstrated that
\end{abstract}

Correspondence to: Professor Shiming Zhang, Department of Neurosurgery, The First Affiliated Hospital of Soochow University, 188 Shizi Street, Suzhou, Jiangsu 215006, P.R. China

E-mail: shmzhang2004@aliyun.com

Dr Yuan Zhang, Department of Radiology, Suzhou Guangji Hospital, 286 Guangji Road, Suzhou, Jiangsu 215006, P.R. China

E-mail: zy18112556628@aliyun.com

*Contributed equally

Key words: postoperative vascular restenosis, vascular smooth muscle cells, nuclear factor $\kappa \mathrm{B}, \mathrm{PCNA}$ following treatment with synthetic E-selectin, the levels of $\mathrm{NF}-\kappa \mathrm{B}$ and the inflammatory response, as well as the presence of PCNA-positive cells, were significantly reduced $(\mathrm{P}<0.01)$. In conclusion, the results of the present study suggested that synthetic E-selectin may exert anti-inflammatory and anti-restenotic effects following vascular anastomosis in vivo.

\section{Introduction}

Cerebrovascular disease has been identified as the third leading cause of mortality (1), and cerebrovascular accidents are among the main causes of mortality and disability worldwide with great clinical and socioeconomic impact. Ischemic stroke accounts for $\sim 80 \%$ of all cerebrovascular accidents worldwide (2), while carotid artery stenosis or occlusion accounts for $15-20 \%$ of ischemic stroke (3), as it can result in brain ischemia and infarction. Carotid endarterectomy is the standard operation for the prevention of cerebral infarction, whereas vascular restenosis is one of the major complications following vascular anastomosis, often causing failure of the surgery (4). The 3 -year rate of restenosis of $\geq 50 \%$ of anastomotic sites following carotid endarterectomy has been reported as 5\% (5). Therefore, the prevention of restenosis following vascular anastomosis is of great significance for patients at risk of cerebrovascular accidents.

Postoperative vascular restenosis is a complex pathophysiological process. Excessive proliferation and migration of vascular smooth muscle cells (VSMCs) are critical for the development of restenosis, and inflammatory responses are involved in the molecular mechanisms underlying these events (6). Following surgically-induced vascular anastomosis, the injured endangium and the exposed subendothelial tissues have been demonstrated to induce the expression of numerous biologically active factors, including chemokines, cytokines and cell adhesion molecules, which can trigger inflammatory responses, leading to leukocyte adhesion and platelet activation, and can enhance VSMC proliferation and migration (7). Numerous alterations have been reported to occur in VSMCs following vascular injury, including their transition from a contractile phenotype to an active phenotype with secretory functions; secretory VSMCs can produce paracrine mediators, including tumor necrosis factor (TNF)- $\alpha$ and interleukin (IL)-6 (8). This phenotypic alteration further enhances the 
synthesis of cytokines and growth factors, which promote the proliferation and migration of VSMCs and maintain their active state in the inflammatory environment. This vicious cycle of events causes the sustained production of cytokines and growth factors that ultimately lead to the development of intimal hyperplasia. Therefore, it may be hypothesized that the inhibition of the inflammatory response following vascular injury is a promising strategy to suppress VSMC proliferation, and thus vascular hyperplasia (9).

TNF- $\alpha$ and IL- 6 are critical mediators during inflammatory responses. TNF- $\alpha$ and IL- 6 have been reported to be involved in nuclear factor (NF)- $\mathrm{B}$-mediated pathways (10), which can stimulate DNA synthesis and intercellular adhesion molecule-1 expression. These molecular pathways have been revealed to be involved in VSMC proliferation and migration, as well as fibroblast proliferation, thus leading to intimal hyperplasia $(11,12)$. NF- $\kappa \mathrm{B}$-mediated signaling pathways have been reported to regulate the transcription of several target genes (13). In the absence of appropriate stimuli, NF- $\kappa \mathrm{B}$ and its inhibitory factor $\kappa \mathrm{B}(\mathrm{I} \kappa \mathrm{B})$ combine to form an inactive complex in the cytoplasm. Various stimuli can activate the I $\mathrm{B} B$ kinase in the cell membrane to promote $\mathrm{I} \kappa \mathrm{B}$ phosphorylation and degradation, leading to the release of active $\mathrm{NF}-\kappa \mathrm{B} . \mathrm{NF}-\kappa \mathrm{B}$ can then translocate to the nucleus, where it can modulate the transcription of several proinflammatory genes, including TNF- $\alpha$ and IL-6. These proinflammatory factors have been reported to mediate chronic inflammatory responses in the vascular endothelium and promote VSMC proliferation and migration to the tunica intima (14). Proliferating cell nuclear antigen (PCNA) has been identified as an accessory protein of DNA polymerase $\delta$, which is involved in DNA replication, and is thus critical for the initiation of cellular proliferation. The expression levels of PCNA have been demonstrated to reliably reflect the rate of cellular proliferation (15). Therefore, the detection of PCNA expression levels in vascular tissue allows the evaluation of VSMC proliferation. A previous study reported that synthetic selectin can inhibit cerebral ischemia-reperfusion injury in rats (16). Thus, in the present study synthetic E-selectin was selected for further evaluation.

In the present study, rats underwent vascular anastomosis and were treated with synthetic E-selectin in order to investigate the putative inhibitory effects of E-selectin on VSMC proliferation and thus arterial restenosis. Synthetic E-selectin was demonstrated to suppress the expression of inflammatory factors, thus suggesting that it may be able to attenuate inflammatory responses and inhibit VSMC proliferation.

\section{Materials and methods}

Animals. A total of 90 adult male Sprague-Dawley rats (age, 8-10 weeks; weight, 250-300 g) were purchased from the Animal Center of the Chinese Academy of Sciences (Shanghai, China). The rats were kept in standard cages (5 rats/cage) and housed in temperature- $\left(\sim 25^{\circ} \mathrm{C}\right)$ and humidity(50-60\%) controlled animal quarters, under 12/12 h light/dark cycles with free access to food and water. Care was taken to avoid unnecessary stress and discomfort to the rats throughout the experimental period.

The animal use and care protocols, including all operation procedures, were approved by the Institutional Animal
Care Committee of Soochow University (Jiangsu, China) and conformed to the Guide for the Care and Use of Laboratory Animals by the National Institutes of Health (17).

Carotid artery anastomosis model. Rats were anesthetized with $4 \%$ chloral hydrate $(400 \mathrm{mg} / \mathrm{kg})$ via intraperitoneal injection. The body was placed in the supine position, and the limbs and head were fixed with rubber bands on the operating table. Body temperature was maintained at $37.5 \pm 0.5^{\circ} \mathrm{C}$ with an automatic heating pad (Letica Scientific Instruments, Barcelona, Spain). The anterior part of the neck was shaved and the exposed skin was sterilized. A $\sim 1.5 \mathrm{~cm}$ incision was made along the upper neck midline, and the muscle layer was dissected under a surgical microscope to isolate the right common carotid artery. Two vascular occlusion clips were placed on the artery to temporarily block blood flow; the distance between the clips was $\sim 1 \mathrm{~cm}$. A longitudinal incision was made in the blood vessel wall between the clips and the incision was closed using interrupted sutures (Fig. 1). Following suturing, a Microvascular Doppler (Nanjing Kejin Industrial Co., Ltd, Nanjing, China) was used to monitor blood flow in the proximal and distal end of the anastomosis, to determine whether the anastomosis remained unblocked. A total of $\sim 15$ min elapsed from the initiation of blood vessel blockage to the completion of vascular anastomosis. Then 25 U Heparin (Yan Sheng Co., Shanghai, China) was injected intravenously to prevent the formation of blood clots. The skin was continuously sutured and disinfected. The rats were allowed to recover for $45 \mathrm{~min}$ following surgery. Subsequently, they were returned to their cages and the room temperature was maintained at $25 \pm 1^{\circ} \mathrm{C}$. To prevent dehydration, $20 \mathrm{ml}$ $0.9 \% \mathrm{NaCl}$ solution was injected subcutaneously, immediately following the operation.

Experimental design. Among the total 90 rats, 72 rats survived the carotid endarterectomy and were randomly assigned to the following three groups ( $\mathrm{n}=24$ rats/group): Control, operation and treatment groups. Rats in the treatment group were injected with $10 \mathrm{mg} / \mathrm{kg}$ synthetic E-selectin (Prospec-Tany TechnoGene, Ltd., East Brunswick, NJ, USA) into the femoral vein immediately following surgery; rats in the operation group received an equal volume of saline. The dose of E-selectin was chosen according to Morikawa et al (16). Rats in the control group underwent a temporary 20 min blockage of the right carotid artery without vascular suturing, and received no further interventions.

Sample collection. Serum samples were collected as follows: Rats from the three groups (6 rats/group/day) were anaesthetized with $4 \%$ chloral hydrate $(400 \mathrm{mg} / \mathrm{kg})$ via intraperitoneal injection on postoperative day 1,3,7 and 14, and blood samples ( $4 \mathrm{ml}$ ) were collected from the heart. Blood samples were centrifuged at room temperature for $16 \mathrm{~min}$ at $8,000 \mathrm{x}$ g. The supernatants were cryopreserved at $-20^{\circ} \mathrm{C}$, and serum samples from all postoperative days were collectively tested. Serum levels of TNF- $\alpha$ and IL- 6 were evaluated using enzyme-linked immunosorbent assay (ELISA).

All the rats were euthanized by cervical dislocation following anaesthesia with $4 \%$ chloral hydrate $(400 \mathrm{mg} / \mathrm{kg})$ via intraperitoneal injection. Following euthanasia, vascular tissue 

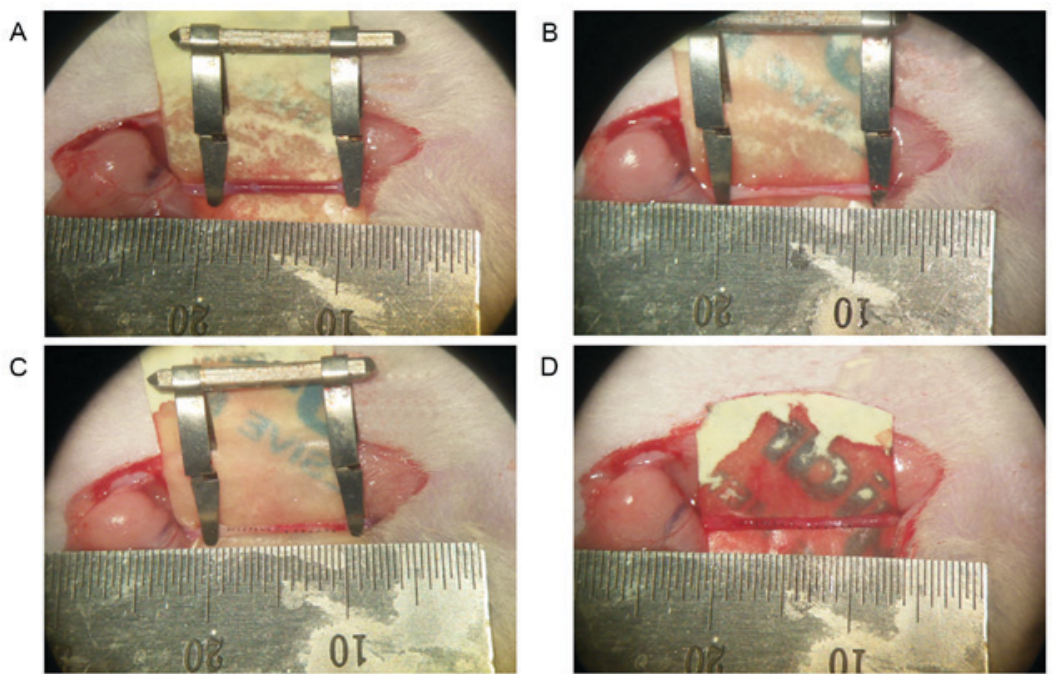

Figure 1. Development of carotid artery anastomosis in adult male rats. (A) Fully exposed carotid artery. (B) A longitudinal $\sim 1$-cm incision was made in the arterial wall. (C) Approximately 15 sutures were used to close the incision. (D) Following the removal of the vascular clips, the sutured vessel demonstrated no obvious stenosis and blood flow remained unobstructed.

samples of rats were collected as follows: On postoperative day 1, 3, 7 and 14, the skin was cut along the original incision and the right common carotid artery was separated. The ends of the anastomosis were clipped and the vascular lumen was flushed with heparinized saline. Vascular tissue samples were collected, fixed and stored in $10 \%$ paraformaldehyde solution at $4{ }^{\circ} \mathrm{C}$ for $24 \mathrm{~h}$. The mRNA and protein expression levels of NF- $\kappa$ B p65 in vascular tissue samples were assessed using western blot analysis and reverse transcription-quantitative polymerase chain reaction (RT-qPCR), respectively. In addition, NF- $\kappa \mathrm{B}$ binding activity was assessed using electrophoretic mobility shift assay (EMSA), and the percentage of PCNA-positive cells in vascular tissue was detected using immunohistochemistry.

ELISA. The serum levels of inflammatory mediators were quantified using specific rat ELISA kits, according to the manufacturers' protocols. The TNF- $\alpha$ ELISA kit (cat. no. RA20035; Bio-Swamp Life Science, Shanghai, China) and the IL-6 kit (cat. no. RA20607; Bio-Swamp Life Science) were used. Briefly, $100 \mu 1$ standard or serum sample was added to each well and the plate was covered with a plate sealer. Plates were incubated for $2 \mathrm{~h}$ at $37^{\circ} \mathrm{C}$, aspirated and $100 \mu \mathrm{l}$ Detection Reagent A working solution was added to each well. The plates were covered with the plate sealer and incubated for $1 \mathrm{~h}$ at $37^{\circ} \mathrm{C}$. Subsequently, the plates were aspirated, washed three times and $100 \mu$ l Detection Reagent B working solution was added to each well. The plates were covered with the plate sealer and incubated for $30 \mathrm{~min}$ at $37^{\circ} \mathrm{C}$. Plates were then aspirated, washed five times, $90 \mu 1$ Substrate Solution was added to each well and plates were covered with a new plate sealer and incubated for $15-25 \mathrm{~min}$ at $37^{\circ} \mathrm{C}$ in the dark. Finally, $50 \mu \mathrm{l}$ Stop Solution was added to each well. Samples were immediately measured at $450 \mathrm{~nm}$ using a microplate reader. Duplicate readings for each standard, control and sample were averaged and the average zero standard optical density (OD) was subtracted. The standard OD curve was plotted using regression analysis to estimate the best fit. The standard curve was then used to estimate the sample concentrations, which were multiplied by the dilution ratio, thus yielding the actual protein concentration in each serum sample.

Immunohistochemistry. Immunohistochemistry was used to evaluate the immunoreactivity of PCNA in paraformaldehyde-fixed paraffin-embedded vascular tissue sections. Briefly, the sutures in the blood vessel walls were removed, the tissue was fixed in $4 \%$ paraformaldehyde at $4^{\circ} \mathrm{C}$ for $24 \mathrm{~h}$ and then embedded in paraffin. Tissue samples were sliced coronally into $4 \mu \mathrm{m}$ sections, which were then deparaffinized and rehydrated in graded concentrations of ethanol in distilled water. Endogenous peroxidase activity was blocked with $3 \% \mathrm{H}_{2} \mathrm{O}_{2}$ for $5 \mathrm{~min}$ at room temperature, followed by a brief rinse in distilled water and a 15-min wash in PBS. Sections were placed in $10 \mathrm{mM}$ citrate buffer ( $\mathrm{pH}$ 6.0) and heated in a microwave oven at $95^{\circ} \mathrm{C}$ for $30 \mathrm{~min}$ for antigen retrieval. Sections were cooled at room temperature for $20 \mathrm{~min}$ and rinsed in PBS. Non-specific binding was blocked by a 40-min incubation in Immunol staining blocking buffer (cat. no. P0102; Beyotime Institute of Biotechnology, Haimen, China) at $37^{\circ} \mathrm{C}$. Sections were then incubated with an anti-PCNA mouse monoclonal antibody (cat. no. ab29; 1:200; Abcam, Cambridge, MA, USA) for $1 \mathrm{~h}$ at room temperature, followed by a 15 -min wash in PBS. Following incubation with biotinylated goat anti-mouse secondary antibody (cat. no. PAB10760; 1:500; Abnova, Taipei, Taiwan) and streptavidin-biotin complex (Wuhan Boster Biological Technology, Ltd., Wuhan, China) for $30 \mathrm{~min}$ at room temperature, 3,3'-diaminobenzidine was used for the chromogenic detection of immunoreactive complexes, and counterstaining was performed with hematoxylin. Subsequently, the sections were dehydrated using an ethanol gradient of 80,95 and $100 \%$, and then covered with coverslips. The sections were examined by a light microscope (CX23; Olympus Corporation, Tokyo, Japan) and the cells counted; cells with intense or moderate brown staining were classified as PCNA-positive, whereas cells with weak or no staining were classified as PCNA-negative. The number of PCNA-positive 
cells in each section was determined in 10 randomly selected microscope fields throughout similar regions of the studied vessel (x400 magnification), and the mean PCNA-positive cell number per visual field was calculated.

Extraction of nuclear proteins. Nuclear proteins were extracted and quantified as previously described (18). Briefly, frozen vascular tissue samples were homogenized with $1 \mathrm{ml}$ lysis buffer, composed of $10 \mathrm{mM}$ HEPES (pH 7.9), $2 \mathrm{mM} \mathrm{MgCl}_{2}$, $10 \mathrm{mM} \mathrm{KCl}, 0.1 \mathrm{mM}$ EDTA, $1 \mathrm{mM}$ dithiothreitol (DTT) and $0.5 \mathrm{mM}$ phenylmethylsulfonyl fluoride (PMSF), purchased from Sigma-Aldrich; Merck KGaA (Darmstadt, Germany). The homogenates were centrifuged at $1,000 \mathrm{x}$ for $30 \mathrm{sec}$ at $4^{\circ} \mathrm{C}$ to discard tissue fragments. The supernatants were then incubated on ice for $20 \mathrm{~min}$ and centrifuged at 5,000 x $\mathrm{g}$ for $10 \mathrm{~min}$ at $4^{\circ} \mathrm{C}$. The crude nuclear pellets were suspended in $200 \mu \mathrm{l}$ ice-cold buffer, containing $20 \mathrm{mM}$ HEPES (pH 7.9), $25 \%$ glycerol, $1.5 \mathrm{mM} \mathrm{MgCl} 2,20 \mathrm{mM} \mathrm{KCl}, 0.1 \mathrm{mM}$ EDTA, $0.5 \mathrm{mM}$ PMSF and $1 \mathrm{mM}$ DTT, and incubated on ice for $30 \mathrm{~min}$ with frequent mixing. The samples were then centrifuged at $12,000 \mathrm{x} \mathrm{g}$ for $15 \mathrm{~min}$ at $4^{\circ} \mathrm{C}$. The supernatants were collected as nuclear extracts and stored at $-80^{\circ} \mathrm{C}$ for further analysis. Protein concentration was determined using a bicinchoninic acid assay kit with bovine serum albumin as the standard (Pierce; Thermo Fisher Scientific, Inc., Waltham, MA, USA).

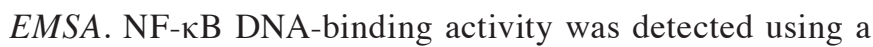
Gel Shift Assay system (Promega Corporation, Madison, WI, USA). The NF- $\kappa$ B consensus oligonucleotide (5'-AGT TGAGGGGACTTTCCCAGGC-3') was 5'-end-labeled with $\left[\gamma-{ }^{32} \mathrm{P}\right]$-adenosine triphosphate (PerkinElmer, Inc., Waltham, MA, USA). Nuclear proteins $(40 \mu \mathrm{g})$ were preincubated in a total volume of $9 \mu \mathrm{l}$ binding buffer, which consisted of $10 \mathrm{mM}$ Tris- $\mathrm{HCl}$ ( $\mathrm{pH} \mathrm{7.5),4 \%} \mathrm{glycerol,} 1 \mathrm{mM} \mathrm{MgCl}_{2}$, $0.5 \mathrm{mM}$ EDTA, $0.5 \mathrm{mM}$ DTT, $50 \mathrm{mM} \mathrm{NaCl}$ and $0.05 \mathrm{mg} / \mathrm{ml}$ poly(deoxyinosinic-deoxycytidylic) acid for $10 \mathrm{~min}$ at room temperature. Following the addition of the ${ }^{32} \mathrm{P}$-labeled oligonucleotide probe, incubation was continued for $20 \mathrm{~min}$ at room temperature. The DNA-protein binding specificity was determined using a competition experiment as a control, with the addition of a 100-fold molar excess of unlabeled NF- $\kappa \mathrm{B}$ oligonucleotide (specific competitor) or unlabeled activating protein 2 oligonucleotide (non-specific competitor) to the binding reaction $10 \mathrm{~min}$ prior to the addition of the ${ }^{32} \mathrm{P}$-labeled probe in the nuclear extract. The reaction was terminated following the addition of $1 \mu 1$ gel loading buffer, and the mixture was subjected to non-denaturing $4 \%$ polyacrylamide gel electrophoresis in Tris-borate-EDTA buffer. The gel was vacuum-dried and exposed to X-ray film (Fuji Hyperfilm, Tokyo, Japan) at $-70^{\circ} \mathrm{C}$ using an intensifying screen (Medical Devices Co., Ltd., Zhejiang, China). The relative intensity of radiolabeled bands was analyzed by ImageJ version 1.47 (National Institutes of Health, Bethesda, MD, USA).

$R T-q P C R$. mRNA expression levels of NF- $\mathrm{B}$ p 65 were determined in vascular tissue samples using RT-qPCR. Total RNA was extracted using TRIzol ${ }^{\circledR}$ reagent (Invitrogen; Thermo Fisher Scientific, Inc.), according to the manufacturer's protocol. The RNA quality was assessed by gel visualization and spectrophotometric analysis using the
$\mathrm{OD}_{260} / \mathrm{OD}_{280}$ ratio. The quantity of RNA was measured with a spectrophotometer using $\mathrm{OD}_{260}$. According to the manufacturers' protocols, total RNA was reverse transcribed into cDNA using M-MLV Reverse Transcriptase (cat. no. M530B; Promega Corporation) and oligo dT primers (Shanghai ShineGene Molecular Biotech, Inc., Shanghai, China). cDNA was used for RT-qPCR with the Rotor-Gene 3000 real-time PCR cycler (Qiagen China Co., Ltd., Shanghai, China) using SYBR Green as the fluorescent probe. The following primers were used: NF- $\kappa \mathrm{B}$, sense 5'-TTTGATAACCGTGCCCCC AA-3', antisense 5'-GCCAGGTCCCGTGAAATACA-3'; and GAPDH, sense 5'-TCTCTGCTCCTCCCTGTTCT-3' and antisense 5'-TACGGCCAAATCCGTTCACA-3'. The reaction mixtures contained diluted cDNA, SYBR Green I Nucleic Acid Gel Stain (Invitrogen; Thermo Fisher Scientific, Inc.), $20 \mu \mathrm{M}$ of each primer and nuclease-free water, to a final volume of $25 \mu \mathrm{l}$. Thermocycling conditions were as follows: Initial denaturation at $95^{\circ} \mathrm{C}$ for $5 \mathrm{~min}$, followed by 40 cycles of amplification (denaturation at $94^{\circ} \mathrm{C}$ for $30 \mathrm{sec}$, annealing at $55^{\circ} \mathrm{C}$ for $30 \mathrm{sec}$ and extension at $72^{\circ} \mathrm{C}$ for $5 \mathrm{~min}$ ). GAPDH was used as an internal loading control. The $2^{\Delta \Delta C q}$ method was used for normalization (19). All samples were analyzed in triplicate.

Western blot analysis. Western blot analysis was used to determine $\mathrm{NF}-\kappa \mathrm{B}$ p65 protein expression levels. Briefly, frozen vascular tissue samples were lysed in radioimmunoprecipitation buffer (cat. no. P0013; Beyotime Institute of Biotechnology) and centrifuged at 12,000 x g for $20 \mathrm{~min}$ at $4^{\circ} \mathrm{C}$. Protein concentration was determined using the Bradford assay (Nanjing Jiancheng protein assay kit; Nanjing Jiancheng Bioengineering Institute, Nanjing, China). Equal amounts of extracted protein samples $(60 \mu \mathrm{g})$ were separated by $10 \%$ SDS-PAGE and transferred onto a polyvinylidene difluoride membrane (Bio-Rad Laboratories, Inc., Hercules, CA, USA). The membrane was blocked with 5\% skim milk for $2 \mathrm{~h}$ at room temperature and incubated overnight at $4^{\circ} \mathrm{C}$ with anti-NF-кB p65 (1:150; cat. no. SAB4502610; Sigma-Aldrich, Merck KGaA) and anti-GAPDH (1:6,000; cat. no. G9545; Sigma-Aldrich, Merck KGaA) primary antibodies in PBS containing 0.1\% Tween-20 (PBST). Following 6 washes in PBST, the membrane was incubated at room temperature with horseradish peroxidase-conjugated secondary antibody (1:400; cat. no. ab6721; Abcam) for $2 \mathrm{~h}$. The protein bands were visualized using Amersham Enhanced Chemiluminescence Western Blotting Detection Reagent (GE Healthcare Life Sciences, Chalfont, UK) and were exposed to X-ray film. Developed films were digitized using an Epson Perfection 2480 scanner (Epson America, Inc., Long Beach, CA, USA). Blots were semi-quantified by densitometric analysis using ImageJ2x software (National Institutes of Health, Bethesda, MD, USA), and protein expression levels were normalized to GAPDH.

Statistical analysis. The statistical significance of the differences between groups was assessed using one-way analysis of variance, followed by a post hoc Fisher's least significant difference test for multiple comparisons. Data are expressed as the mean \pm standard deviation of at least three independent experiments. $\mathrm{P}<0.05$ was considered to indicate a statistically 
significant difference. Statistical analysis was performed using SPSS software version 12.0 (SPSS, Inc., Chicago, IL, USA).

\section{Results}

General observations. No significant alterations were detected in body weight, temperature, mean arterial blood pressure and injected arterial blood gas data among experimental groups (data not shown). All rats survived for the duration of the experiments, from the induction to the unblocking of experimental anastomoses.

Morphological alterations following arterial anastomosis. Among rats in the operation group, no marked thickening in blood vessels was observed 3 days following anastomosis, and suture adhesion was not obvious. However, peripheral tissue edema developed, which disappeared 7 days post-anastomosis. On day 7, the anastomosis tissue appeared thicker compared with on day 3 , whereas some of the sutures had adhered to the surrounding tissue. On day 14 , granulation tissue development was obvious surrounding the anastomosis, and sutures had thickened, suggesting that intimal hyperplasia had developed. Among rats in the treatment group, thickening and adhesion of vascular anastomoses was less pronounced compared with in the operation group at the corresponding time points (data not shown).

Synthetic E-selectin suppresses $N F-\kappa B$ binding activity. Autoradiography results, following EMSA of $N F-\kappa B$ DNA-binding activity in tissue samples isolated from vascular anastomoses, are presented in Fig. 2. Low NF- $\mathrm{BB}$ binding activity, corresponding to a weak autoradiography signal, was detected in rats in the control group. Conversely, NF- $\kappa \mathrm{B}$ binding activity in anastomosis tissue samples was significantly increased in rats in the operation group compared with in the control group $(\mathrm{P}<0.01 ;$ Fig. 2$)$. Following treatment with synthetic E-selectin, NF- $\kappa \mathrm{B}$ binding activity appeared to be significantly downregulated in the vascular tissue surrounding the anastomotic site compared with the operation group $(\mathrm{P}<0.05)$. These results suggested that synthetic E-selectin may prevent $\mathrm{NF}-\kappa \mathrm{B}$ activation and its subsequent nuclear translocation.

Synthetic E-selectin downregulates $N F-\kappa B$ p 65 protein expression. Western blot analysis was used to evaluate the alterations in $\mathrm{NF}-\kappa \mathrm{B}$ p 65 protein expression levels following arterial anastomosis. NF- $\mathrm{B}$ p 65 protein expression levels remained consistently low in rats in the control group at the various time points (Fig. 3). Conversely, NF- $\kappa \mathrm{B}$ p65 levels were significantly upregulated in vascular tissue surrounding the anastomotic site isolated from rats in the operation group, suggesting the activation of the $N F-\kappa B$ pathway. NF- $\kappa$ B p 65 protein expression levels in rats treated with synthetic E-selectin were significantly lower at the corresponding time points following anastomosis compared with in rats from the operation group $(\mathrm{P}<0.01$; Fig. 3). These results suggested that synthetic E-selectin may inhibit the upregulation in NF- $\kappa \mathrm{B}$ expression following carotid artery anastomosis.

Synthetic E-selectin downregulates $N F-\kappa B$ p 65 mRNA expression. RT-qPCR was used to investigate alterations in the gene

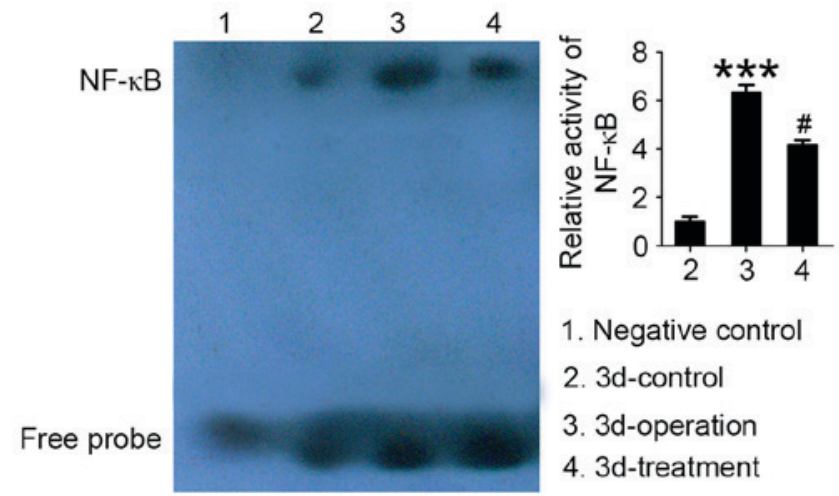

Figure 2. Gel electrophoresis mobility shift assay was used to evaluate the DNA-binding activity of NF- $\mathrm{KB}$ in vascular tissue samples isolated from the perianastomotic site 3 days post-anastomosis. Representative autoradiography results are presented ( $\mathrm{n}=6$ rats/group). Relative levels of NF- $\mathrm{\kappa B}$ DNA-binding activity were semi-quantified using computer-assisted densitometric scanning and are expressed as arbitrary densitometric units. Data are expressed as the mean \pm standard deviation. ${ }^{* * * *} \mathrm{P}<0.01$ vs. the control group; ${ }^{\#} \mathrm{P}<0.05$ vs. the operation group. NF, nuclear factor; $3 \mathrm{~d}, 3$ days.
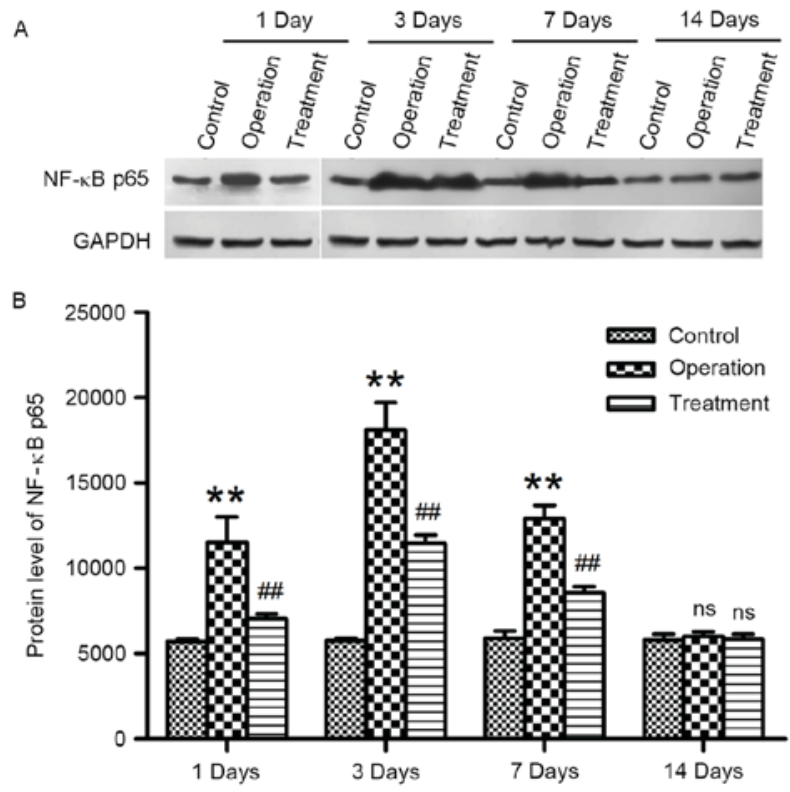

Figure 3. Western blot analysis was used to evaluate the protein expression levels of NF- $\kappa \mathrm{B}$ p65 in vascular tissue samples isolated from the perianastomotic site. (A) Representative blot demonstrates NF- $\kappa$ B p65 levels on days 1, 3,7 and 14 post-anastomosis ( $n=6$ rats/group). (B) Densitometric analysis was used for blot semi-quantification. Data are expressed as the mean \pm standard deviation. ${ }^{* *} \mathrm{P}<0.01$ vs. the control group; ${ }^{\# \#} \mathrm{P}<0.01$ vs. the operation group. $\mathrm{NF}$, nuclear factor; ns, not significant.

expression of $\mathrm{NF}-\kappa \mathrm{B}$ p65 following arterial anastomosis. $\mathrm{NF}-\kappa \mathrm{B}$ p65 mRNA expression levels remained consistently low in rats in the control group throughout the duration of the study. Conversely, following carotid artery anastomosis, $\mathrm{NF}-\kappa \mathrm{B}$ p65 mRNA expression appeared to be significantly upregulated ( $\mathrm{P}<0.05$; Fig. 4). Treatment with synthetic E-selectin was demonstrated to significantly downregulate NF- $\kappa$ B p65 mRNA expression levels compared with the operation group at the corresponding time points post-anastomosis $(\mathrm{P}<0.05$; Fig. 4). These results suggested that synthetic E-selectin may suppress NF- $\kappa \mathrm{B}$ expression at the mRNA level. 
Synthetic E-selectin reduces serum concentrations of TNF- $\alpha$ and IL-6. The concentrations of TNF- $\alpha$ and IL- 6 in rat serum samples were determined using ELISA. TNF- $\alpha$ and IL-6 concentrations in rats from the control group remained low throughout the duration of the experiments. Following anastomosis, the serum concentrations of TNF- $\alpha$ and IL- 6 were significantly increased on days 1,3 and 7 post-surgery compared with the control group (Fig. 5); serum concentrations peaked on day 3. Serum samples isolated from E-selectin-treated rats following anastomosis exhibited significantly reduced TNF- $\alpha$ and IL-6 concentrations compared with samples from the operation group $(\mathrm{P}<0.01$; Fig. 5$)$. However, no statistically significant differences were detected among the control, operation and treatment groups on day 14 post-surgery. These results indicated that treatment with synthetic E-selectin may prevent the increase in serum TNF- $\alpha$ and IL-6 levels following arterial anastomosis.

Synthetic E-selectin suppresses VSMC proliferation. PCNA levels have been reported to reflect the degree of cellular proliferation (15). Therefore, in the present study, PCNA immunoreactivity was investigated in vascular tissue surrounding the anastomotic site in order to assess VSMC proliferation. Rats in the control group exhibited negligible numbers of PCNA-positive cells at the various time points (Fig. 6). PCNA-positive cell numbers were significantly increased in rats in the operation group as early as 3 days post-anastomosis; PCNA immunoreactivity remained high throughout the course of the study (Fig. 6). Notably, rats treated with synthetic E-selectin demonstrated significantly reduced PCNA-positive cell numbers following anastomosis compared with rats in the operation group $(\mathrm{P}<0.01$; Fig. 6$)$. These results suggested that synthetic E-selectin administration post-anastomosis may suppress the proliferative capabilities of VSMCs.

\section{Discussion}

The present study demonstrated that intimal hyperplasia was induced following carotid artery anastomosis, whereas it could be effectively suppressed by the administration of synthetic E-selectin. The molecular mechanisms underlying the effects of synthetic E-selectin on neointimal formation were also investigated. A significant increase in the production of the proinflammatory cytokines TNF- $\alpha$ and IL-6, which has been reported to promote VSMC proliferation (8), was detected following vascular injury. In addition, NF- $\kappa \mathrm{B}$ mRNA and protein expression levels were also revealed to be upregulated post-anastomosis. Notably, TNF- $\alpha$ and IL-6 serum levels were significantly decreased following treatment with synthetic E-selectin, which also appeared to suppress NF-kB-mediated signaling. In addition, the results demonstrated that synthetic E-selectin-induced suppression of the NF- $\mathrm{KB}$ pathway was primarily in the early stage after anastomosis. Furthermore, synthetic E-selectin administration was revealed to inhibit VSMC proliferation, thus suggesting that it may be able to reduce postoperative vascular restenosis.

Neointimal hyperplasia has been identified as a critical mechanism during the development of restenosis that often follows vascular anastomosis (20). VSMC proliferation has been implicated in intimal hyperplasia; following vascular injury,

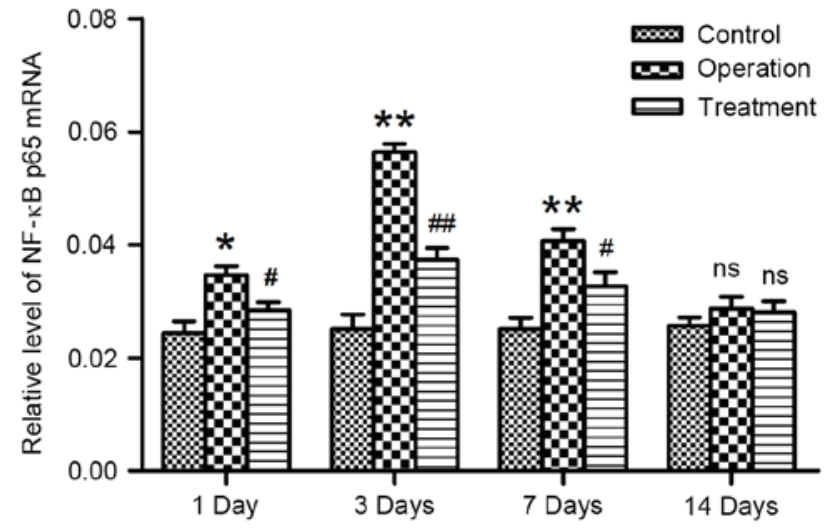

Figure 4. Reverse transcription-quantitative polymerase chain reaction was used to evaluate the mRNA expression levels of NF- $\kappa \mathrm{B}$ p65 in vascular tissue samples isolated from the perianastomotic site on days 1, 3, 7 and 14 post-anastomosis ( $\mathrm{n}=6 \mathrm{rats} / \mathrm{group})$. Data are expressed as the mean \pm standard deviation. ${ }^{*} \mathrm{P}<0.05,{ }^{* *} \mathrm{P}<0.01$ vs. the control group; ${ }^{\#} \mathrm{P}<0.05,{ }^{\# \#} \mathrm{P}<0.01$ vs. the operation group. NF, nuclear factor; ns, not significant.
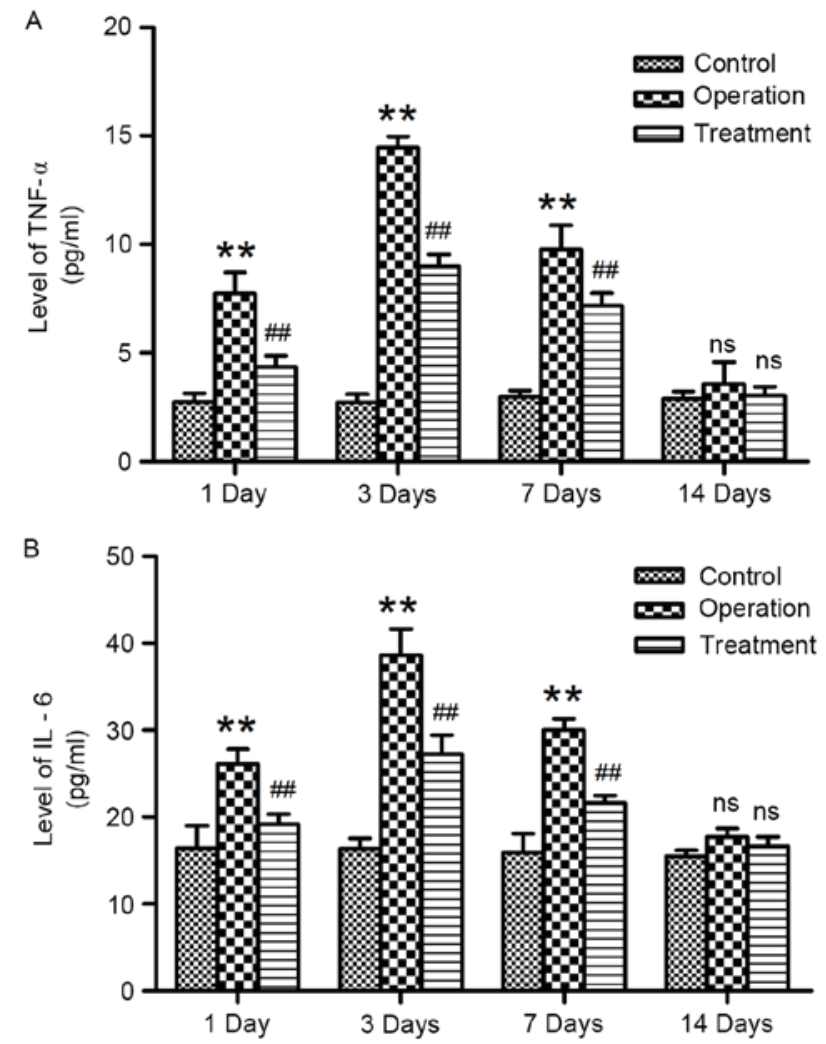

Figure 5. ELISA was used to evaluate the concentration of the proinflammatory cytokines (A) TNF- $\alpha$ and (B) IL-6 in rat serum samples isolated on days $1,3,7$ and 14 post-anastomosis ( $n=6$ rats/group). Data are expressed as the mean \pm standard deviation. ${ }^{* *} \mathrm{P}<0.01$ vs. the control group; ${ }^{\# \#} \mathrm{P}<0.01$ vs. the operation group. TNF, tumor necrosis factor; IL, interleukin; ns, not significant.

VSMCs have been reported to undergo phenotypic alteration from a contractile to a secretory type (8). Since their proliferative and migratory capabilities are thus potentiated, VSMCs can migrate from the basement membrane to the tunica intima, resulting in vascular wall thickening and luminal stenosis (21). However, the molecular mechanisms involved in the phenotypic transformation of VSMCs have yet to be elucidated. 

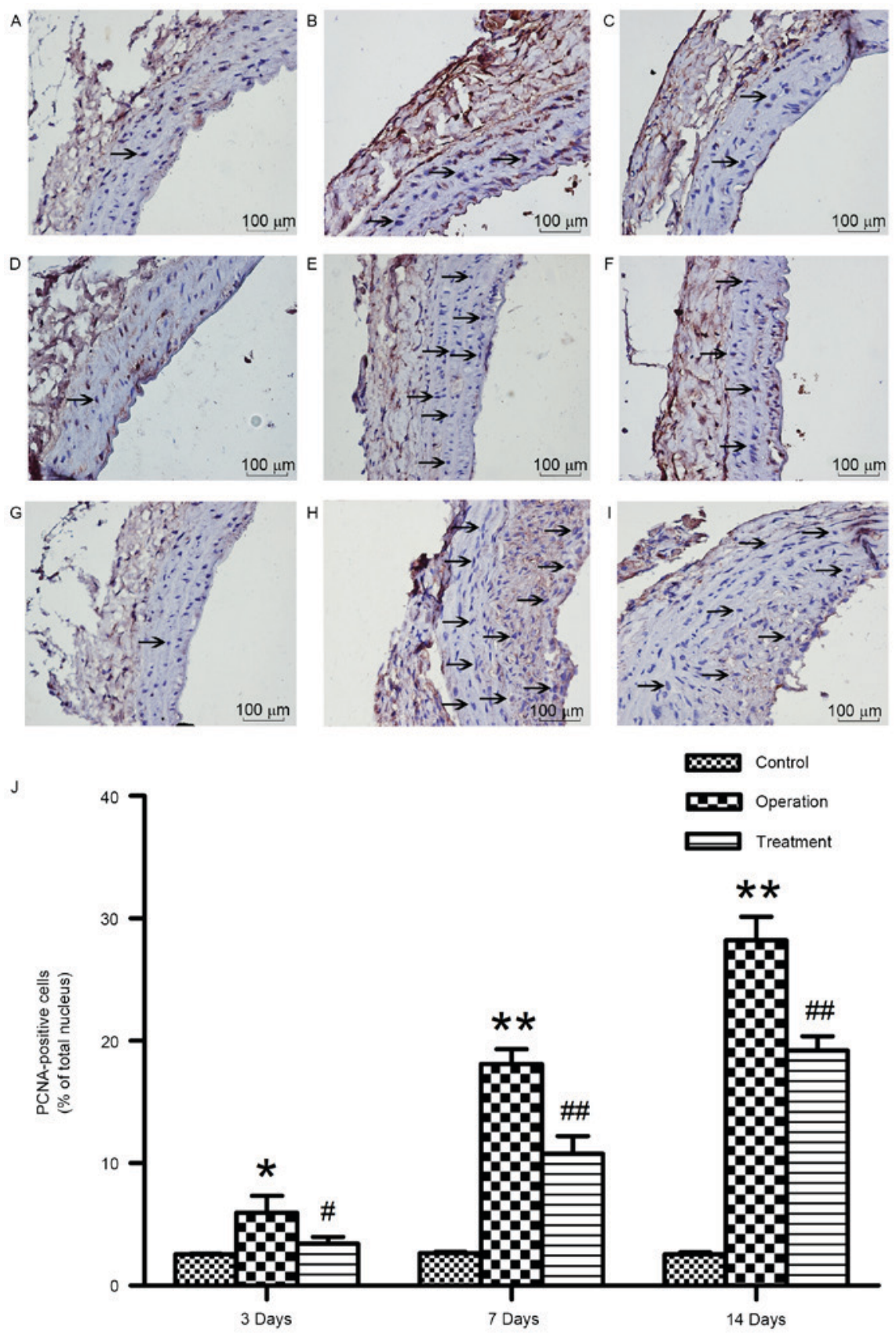

Figure 6. Immunohistochemistry was used to evaluate the numbers of PCNA-positive cells in vascular tissue samples isolated from the perianastomotic site on days 3, 7 and 14 post-anastomosis ( $\mathrm{n}=6$ rats/group). (A-I) Representative photomicrographs of PCNA-positive staining were captured under $\mathrm{x} 400$ magnification (scale bars, $100 \mu \mathrm{m}$ ). (A, D and G) Negligible PCNA expression was detected in control tissue samples on days 3, 7 and 14, respectively. Low numbers of PCNA-positive cells were detected in samples from the (B) operation and (C) treatment groups on day 3 post-anastomosis. Moderate PCNA expression was detected in samples from the (E) operation and (F) treatment groups on day 7 post-anastomosis. Increased numbers of PCNA-positive cells were detected in samples from the (H) operation and (I) treatment groups on day 14 post-anastomosis. Arrows indicate representative PCNA-positive cells. (J) The percentage of PCNA-positive cells was significantly lower in samples from the treatment group compared with in samples from the operation group. Data are expressed as the mean \pm standard deviation. ${ }^{*} \mathrm{P}<0.05,{ }^{* *} \mathrm{P}<0.01$ vs. the control group; ${ }^{\#} \mathrm{P}<0.05,{ }^{\# \#} \mathrm{P}<0.01$ vs. the operation group. PCNA, proliferating cell nuclear antigen.

The pathophysiological mechanisms underlying postoperative arterial restenosis have been reported to include aberrant inflammation that follows vascular injury $(22,23)$. The proinflammatory cytokines TNF- $\alpha$ and IL- 6 are critical in the development of inflammation following vascular injury, as inflammatory cells release large amounts of TNF- $\alpha$ and IL-6, which have been reported to participate in the pathological processes leading to arterial wall damage (24). Selzman et al (12) demonstrated that TNF- $\alpha$ induced VSMC proliferation via activating the NF- $\mathrm{KB}$ pathway. In addition, following NF- $\kappa$ B activation in VSMCs, IL-6 mRNA expression has been revealed to be enhanced, leading to the induction of inflammatory responses in the vascular wall (25). The present study demonstrated that TNF- $\alpha$ and IL- 6 levels began to increase on day 1 post-anastomosis and peaked on day 3; by day 7 they had begun to decrease, returning to physiological levels by day 14 post-surgery. Furthermore, a corresponding increase was detected in the number of PCNA-positive cells. Notably, following treatment with synthetic E-selectin, a decrease in TNF- $\alpha$ and IL-6 serum levels was apparent, which 
was accompanied by a marked decrease in PCNA-positive cell numbers in vascular tissue surrounding the site of anastomosis. These results suggested that IL- 6 and TNF- $\alpha$ may be involved in VSMC proliferation underlying the development of stenosis during the early postoperative stages. Therefore, it may be hypothesized that TNF- $\alpha$ and IL- 6 may be associated with the proliferation and migration of VSMCs.

In the present study, NF- $\kappa \mathrm{B}$ activation in VSMCs appeared to accompany the upregulation in TNF- $\alpha$ and IL- 6 serum levels. Activated NF- $\kappa \mathrm{B}$ has been reported to enhance the transcription of proinflammatory genes, thus promoting the release of several factors that mediate inflammation and promote VSMC proliferation (25). Sekiguchi et al (26) demonstrated that angiotensin II promoted the expression of proinflammatory cytokines, via inducing $\mathrm{NF}-\kappa \mathrm{B}$ activation, whereas the inhibition of $\mathrm{NF}-\kappa \mathrm{B}$ activity was revealed to suppress the expression of inflammatory factors. The involvement of $\mathrm{NF}-\kappa \mathrm{B}$ in cell cycle regulation has also been reported. $\mathrm{NF}-\kappa \mathrm{B}$ has been demonstrated to bind the promoter of the cell cycle-associated protein cyclin D1 and activate its transcription, thus enhancing cell cycle progression from $G_{1}$ to $S$ phase and promoting cellular proliferation (27). $\mathrm{NF}-\kappa \mathrm{B}-$ mediated pathways have also been reported to underlie the pathophysiological processes during VSMC proliferation (28). $\mathrm{NF}-\kappa \mathrm{B}$ inhibitors and decoy oligonucleotides have been revealed to reduce macrophage recruitment and VSMC accumulation in experimental vein grafts (29-31). The present study demonstrated that treatment with synthetic E-selectin effectively suppressed the production and activation of $N F-\kappa B$, which was accompanied by the corresponding production of inflammatory cytokine levels and VSMC proliferation.

The present study evaluated the effects of synthetic E-selectin on NF- $\mathrm{BB}$-mediated pathways following arterial anastomosis. Serum levels of the proinflammatory factors TNF- $\alpha$ and IL- 6 were revealed to be significantly upregulated post-injury, thus suggesting that these factors may act directly on VSMCs to promote their proliferation and migration during the progression of restenosis. The present results suggested that following its activation and nuclear translocation, $\mathrm{NF}-\kappa \mathrm{B}$ may enhance the transcription of inflammatory mediators and promote cellular proliferation, which may in turn trigger the release of more inflammatory mediators and further promote VSMC proliferation and migration. Furthermore, NF- $\kappa \mathrm{B}$ levels appeared to peak 3 days post-anastomosis. At this time point, inflammatory factor levels were also at their highest, and PCNA-positive cell numbers appeared to be increased, indicating the initiation of VSMC proliferation. Synthetic E-selectin was revealed to significantly inhibit NF- $\kappa$ B activation, downregulate the levels of inflammatory mediators, and reduce the number of PCNA-positive cells, thus suggesting that it may be able to inhibit VSMC proliferation and attenuate neointimal hyperplasia. Therefore, it may be hypothesized that the molecular mechanisms underlying the inhibitory effects of synthetic E-selectin on VSMC proliferation may involve the inhibition of NF- $\mathrm{B}$-mediated pathways. Notably, previous studies have reported that ethanol extracts of Prunella vulgaris and Akebia quinata exerted their anti-inflammatory effects via inhibiting the p38 mitogen-activated protein kinase (MAPK) /extracellular signal-regulated kinase (ERK) /NF- $\mathrm{B}$ signaling pathway in TNF- $\alpha$-stimulated human aortic smooth muscle cells $(26,27)$. However, whether E-selectin may be involved in p38 MAPK/ERK/NF- $\mathrm{B}$ signaling pathways during inflammatory responses in VSMCs following carotid artery anastomosis remains to be elucidated.

In conclusion, the present study suggested that following treatment with synthetic E-selectin, the proliferative and migratory capabilities of VSMCs were significantly decreased. Furthermore, synthetic E-selectin was demonstrated to suppress the production and activation of $\mathrm{NF}-\kappa \mathrm{B}$, the production of the proinflammatory cytokines TNF- $\alpha$ and IL-6, as well as downregulate PCNA-positive cells in the perianastomotic tissue. Therefore, it may be hypothesized that synthetic E-selectin is able to inhibit VSMC proliferation and migration, and the molecular mechanisms underlying its actions may involve the suppression of $\mathrm{NF}-\kappa \mathrm{B}$ pathways to inhibit the release of inflammatory cytokines, and thus VSMC proliferation, during the early stages post-anastomosis. However, arterial restenosis is a complex pathological process associated with numerous factors; therefore, the interaction between synthetic E-selectin and the NF- $\mathrm{NB}$ pathway in restenosis requires further study.

\section{Acknowledgements}

The present study was supported by the National Natural Science Foundation of China (grant no. 81371280), Suzhou Basic Research on Science and Technology (grant no. SYS201535) and the Graduate Innovation Program of Jiangsu Province (grant no. CXZZ13_0836).

\section{References}

1. Jia Q, Liu LP and Wang YJ: Stroke in China. Clin Exp Pharmacol Physiol 37: 259-264, 2010.

2. Kim HJ, Kim SK, Park HJ, Chung JH, Chun J, Yun DH and Kim YO: Polymorphisms of IGFI contribute to the development of ischemic stroke. Exp Ther Med 3: 93-98, 2012.

3. Chaturvedi S, Bruno A, Feasby T, Holloway R, Benavente O, Cohen SN, Cote R, Hess D, Saver J, Spence JD, et al: Carotid endarterectomy-an evidence-based review: Report of the therepeutics and technology assessment subcommittee of the american academy of neurology. Neurology 65: 794-801, 2005.

4. Matter CM, Ma L, von Lukowicz T, Meier P, Lohmann C, Zhang D, Kilic U, Hofmann E, Ha SW, Hersberger M, et al: Increased balloon-induced inflammation, proliferation, and neointima formation in apolipoprotein $\mathrm{E}$ (ApoE) knockout mice. Stroke 37: 2625-2632, 2006.

5. Arguizan C, Tringuart L, Touboul PJ, Long A, Feasson S, Terriat B, Gobin-Metteil MP, Guidolin B, Cohen S and Mas JL; EVA-3S Investigators: Restenosis is more frequent after carotid stenting than after endarterectomy: The EVA-3S study. Stroke 42: 1015-1020, 2011.

6. Matter CM, Chadjichristos CE, Meier P, von Lukowicz T, Lohmann C, Schuler PK, Zhang D, Odermatt B, Hofmann E, Brunner T, et al: Role of endogenous Fas (CD95/Apo-1) ligand in balloon-induced apoptosis, inflammation, and neointima formation. Circulation 113: 1879-1887, 2006.

7. Chaturvedi S, Bruno A, Feasby T, Holloway R, Benavente O, Cohen SN, Cote R, Hess D, Saver J, Spence JD, et al: Carotid endarterectomy-an evidence-based review: Report of the therepeutics and technology assessment subcommittee of the american academy of neurology. Neurology 65: 794-801, 2005.

8. Hay C, Micko C, Prescott MF, Liau G, Robinson K and De Leon H: Differential cell cycle progression patterns of infiltrating leukocytes and resident cells after balloon injury of the rat carotid artery. Arterioscler Thromb Vasc Biol 21: 1948-1954, 2001.

9. Li YT, Swales KE, Thomas GJ, Warner TD and Bishop-Bailey D: Farnesoid X receptor ligands inhibit vascular smooth muscle cell inflammation and migration. Arterioscler Thromb Vasc Biol 27: 2606-2611, 2007. 
10. De Simone V, Franzè E, Ronchetti G, Colantoni A, Fantini MC, Di Fusco D, Sica GS, Sileri P, MacDonald TT, Pallone F, et al: Th17-type cytokines, IL- 6 and TNF- $\alpha$ synergistically activate STAT3 and NF- $\kappa$ B to promote colorectal cancer cell growth. Oncogene 34: 3493-3503, 2015.

11. Couffinhal T, Duplàa C, Labat L, Lamaziere JM, Moreau C, Printseva $\mathrm{O}$ and Bonnet J: Tumor necrosis factor-alpha stimulates ICAM-1 expression in human vascular smooth muscle cells. Arterioscler Thromb 13: 407-414, 1993.

12. Selzman CH, Shames BD, Reznikov LL, Miller SA, Meng X, Barton HA, Werman A, Harken AH, Dinarello CA and Banerjee A: Liposomal delivery of purified inhibitory-kappBalpha inhibits tumor necrosis factor-alpha-induced human vascular smooth muscle proliferation. Circ Res 84: 867-875, 1999.

13. Nurmi A, Lindsberg PJ, Koistinaho M, Zhang W, Juettler E, Karjalainen-Lindsberg ML, Weih F, Frank N, Schwaninger M and Koistinaho J: Nuclear factor-kappaB contributes to infarction after permanent focal ischemia. Stroke 35: 987-991, 2004.

14. Williams AJ, Hale SL, Moffett JR, Dave JR, Elliott PJ, Adams J and Tortella FC: Delayed treatment with MLN519 reduces infarction and associated neurologic deficit caused by focal ischemic brain injury in rats via antiinflammatory mechanisms involving nuclear factor-kappaB activation, gliosis, and leukocyte infiltration. J Cereb Blood Flow Metab 23: 75-87, 2003.

15. Ross G, Jiang Y, Landberg G, Nielsen NH, Zhang P and Lee MY: Determination of the epitope of an inhibitory antibody to proliferating cell nuclear antigen. Exp Cell Res 226 208-213, 1996

16. Morikawa E, Zhang SM, Seko Y, Toyoda T and Kirino T: Treatment of focal cerebral ischemia with synthetic oligopeptide corresponding to lectin domain of selectin. Stroke 27: 951-955, 1996.

17. National Research Council (US) Committee for the Update of the Guide for the Care and Use of Laboratory Animals: Guide for the Care and Use of Laboratory Animals. 8th edition. Washington (DC): National Academies Press (US), 2011.

18. Chen G, Shi JX, Hang CH, Xie W, Liu J and Liu X: Inhibitory effect on cerebral inflammatory agents that accompany traumatic brain injury in a rat model: A potential neuroprotective mechanism of recombinant human erythropoietin (rhEPO). Neurosci Lett 425: 177-182, 2007

19. Livak KJ and Schmittgen TD: Analysis of relative gene expression data using real-time quantitative PCR and the 2(-Delta Delta C(T)) Method. Methods 25: 402-408, 2001.

20. Bassiouny HS, White S, Glagov S, Choi E, Giddens DP and Zarins CK: Anastomotic intimal hyperplasia: Mechanical injury or flow induced. J Vasc Surg 15: 708-716, 1992.

21. Austin GE, Ratliff NB, Hollman J, Tabei S and Phillips DF: Intimal proliferation of smooth muscle cells as an explanation for recurrent coronary artery stenosis after percutaneous transluminal coronary angioplasty. J Am Coll Cardiol 6: 369-375, 1985
22. Hong YJ, Jeong MH, Song SJ, Sim DS, Kim JH, Lim KS Hachinohe D, Ahmed K, Hwang SH, Lee MG, et al: Effects of ramiprilat-coated stents on neointimal hyperplasia, inflammation, and arterial healing in a porcine coronary restenosis model. Korean Circ J 41: 535-541, 2011.

23. Zhou XC, Huang RC, Zhang B, Yin D, Liang B, Wang SP, Guan QG, Sun XZ, Miao ZL, He XZ, et al: Inflammation inhibitory effects of sirolimus and paclitaxel-eluting stents on interleukin-1 $\beta$-induced coronary artery in-stent restenosis in pigs. Chin Med J (Engl) 123: 2405-2409, 2010.

24. Warner SJ and Libby P: Human vascular smooth muscle cells. Target for and source of tumor necrosis factor. J Immunol 142: 100-109, 1989.

25. Kranzhöfer R, Schmidt J, Pfeiffer CA, Hagl S, Libby P and Kübler W: Angiotensin induces inflammatory activation of human vascular smooth muscle cells. Arterioscler Thromb Vasc Biol 19: 1623-1629, 1999.

26. Sekiguchi K, Li X, Coker M, Flesch M, Barger PM, Sivasubramanian $N$ and Mann DL: Cross-regulation between the renin-angiotensin system and inflammatory mediators in cardiac hypertrophy and failure. Cardiovasc Res 63 : 433-442, 2004.

27. Hinz M, Krappmann D, Eichten A, Heder A, Scheidereit C and Strauss M: NF-kappaB function in growth control: Regulation of cyclin D1 expression and G0/G1-to-S-phase transition. Mol Cell Biol 19: 2690-2698, 1999.

28. Ramana KV, Chandra D, Srivastava S, Bhatnagar A, Aggarwal BB and Srivastava SK: Aldose reductase mediates mitogenic signaling in vascular smooth muscle cells. J Biol Chem 277: 32063-32070, 2002

29. Shimizu N, Azuma N, Nishikawa T, Hirata S, Morishita R, Kaneda Y and Sasajima T: Effect on vein graft intimal hyperplasia of nuclear factor-kB decoy transfection using the second generation of HVJ vector. J Cardiovasc Surg (Torino) 48: 463-470, 2007

30. Miyake T, Aoki M, Shiraya S, Tanemoto K, Ogihara T, Kaneda Y and Morishita R: Inhibitory effects of NFkappaB decoy oligodeoxynucleotides on neointimal hyperplasia in a rabbit vein graft model. J Mol Cell Cardiol 41: 431-440, 2006.

31. Gareus R, Kotsaki E, Xanthoulea S, van der Made I, Gijbels MJ, Kardakaris R, Polykratis A, Kollias G, de Winther MP and Pasparakis M: Endothelial cell-specific NF-kappaB inhibition protects mice from atherosclerosis. Cell Metab 8: 372-383, 2008

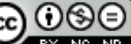

This work is licensed under a Creative Commons Attribution-NonCommercial-NoDerivatives 4.0 International (CC BY-NC-ND 4.0) License. 